\title{
Advances in regional ionospheric mapping over europe
}

\author{
Bruno Zolesi $\left(^{1}\right)$ and Ljiljana R. Cander $\left({ }^{2}\right)$ \\ ( ) Istituto Nazionale di Geofisica, Roma, Italy \\ (') Rutherford Appleton Laboratory, Chilton, U.K.
}

\begin{abstract}
Over the past several years significant advances have been made in all areas of ionospheric modelling and mapping studies. Ionospheric models and maps of varying complexity have been formulated from analytic and simple numerical models that are «user friendly» calculations to complete general circulation models that require hours on today's supercomputers. All have their place and are used in different applications. This review describes progress in regional ionospheric mapping over Europe in the frame of the COST 238 and 251 pro-
jects.
\end{abstract}

Key words ionosphere-radio propagation

\section{Introduction}

The ionosphere, together with other geophysical disciplines like meteorology, oceanography and geomagnetism, plays an important role in basic and applied sciences. It is a cold plasma environment enveloping the Earth which controls and often limits the performance of terrestrial and Earth-space radio systems (support HF radio communications; interrupt transionospheric command, control and communication systems; compromise global positioning networks; induce damaging currents in land-based power grids and transcontinental pipelines, etc.). The accuracy of the derived parameters in these applications depends on the accuracy of the ionospheric specification. This includes the specification of the three-dimensional time-dependent profile of electron den-

Mailing address: Dr. Bruno Zolesi, Istituto Nazionale di Geofisica, U.O. Aeronomia, Via di Vigna Murata 605, 00143 Roma; e-mail: zolesi@ingrm.it sity under quiet and disturbed ionospheric conditions. Specification of the ionosphere can be viewed from its average behaviour (i.e. its climatology) and its hour-to-hour and day-to-day variability (i.e. ionospheric weather), from the radio propagation point of view previously concerned with the ionospheric prediction and later ionospheric forecasting. To develop ionospheric prediction as well as forecasting, applied research on prediction and forecasting must be integrated with advances in ionospheric research. Global approaches to ionospheric weather and climatology may be empirical or they may include first principle modelling activities like those embodied for example in the Utah State TDIM or the University of Alabama FLIP models (see Cander et al., 1996 for review, and references therein).

The best known climatological model of the ionosphere is given by the empirically-derived IRI model (Bilitza, 1992). It provides a monthlyaveraged specification of the diurnally-variable laminar ionosphere driven only by the season (i.e. the month) and the sunspot number. Work on its improvement in different domains such 
as topside, plasma temperatures and ion composition, global and mesoscale electron density distribution is in progress. Related work has also been continuing in more regional refined studies because much more accurate results can be obtained where there are many ionospheric stations. For example a ionospheric $F_{2}$-layer model can be used in the Asia-Oceania Region, known as the AOR mapping, and the Chinese Reference Ionosphere (CRI) can be used in the Chinese subcontinent (Jiao and Wu, 1996; Wu et al., 1996).
Since the ionosphere is very regular over Europe because of the almost clear mid-latitude pattern, there have been attempts within the COST (European Cooperation in the Field of Scientific Research) 238 (PRIME) project to capture its basic characteristics in terms of the key ionospheric characteristics used as input parameters to specify the structure of the electron-density height profile model (Radicella and Zhang, 1995). PRIME models were restricted to the geographical area between latitudes $35^{\circ}-55^{\circ} \mathrm{N}$ and longitudes $10^{\circ} \mathrm{W}-30^{\circ} \mathrm{E}$

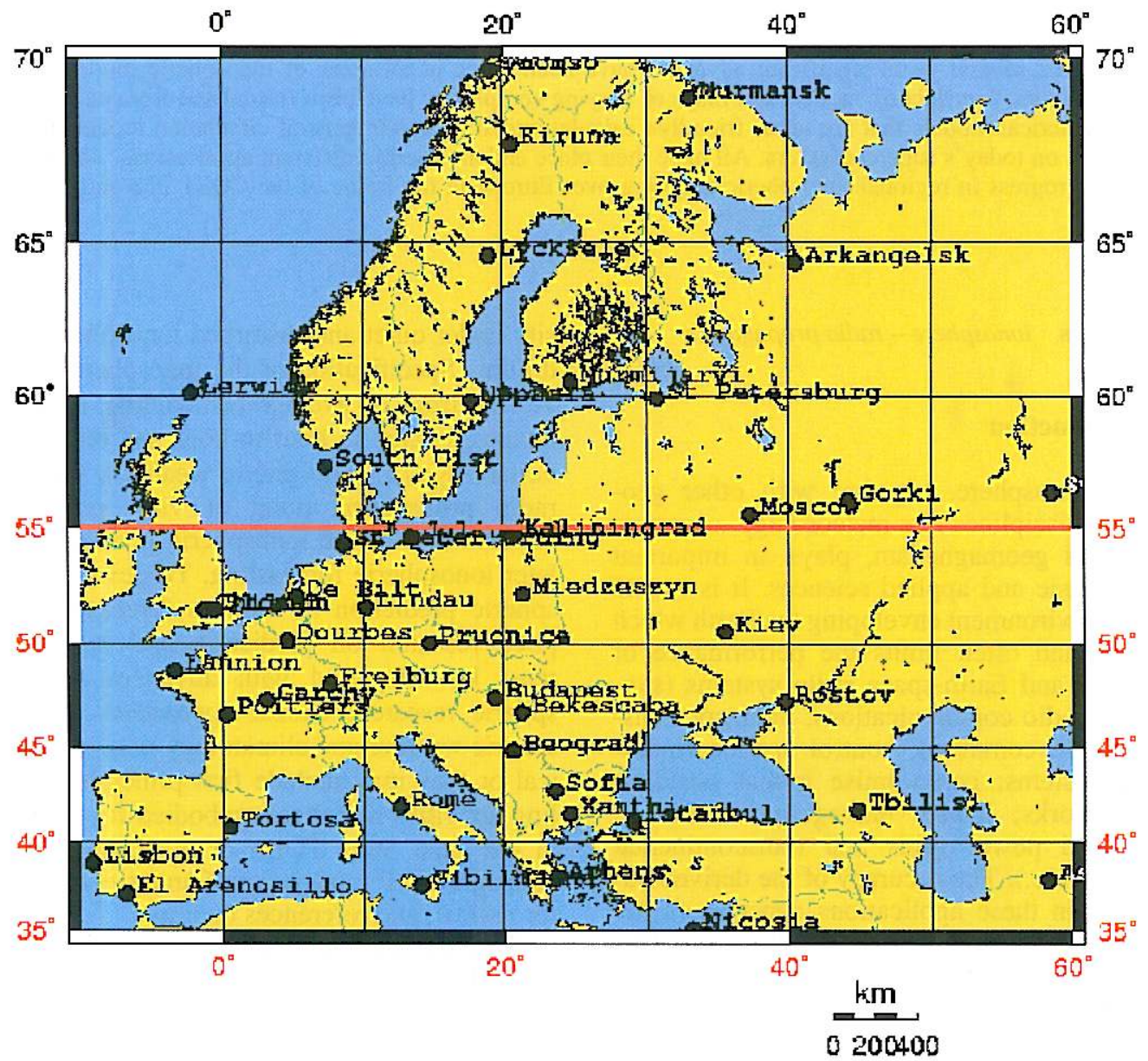

Fig. 1. Map showing the COST 251 area of Europe between latitudes of $35-70^{\circ} \mathrm{N}$ and longitude $10^{\circ} \mathrm{W}-60^{\circ} \mathrm{E}$ and indicating the locations of vertical-incidence ionosonde stations. The COST 238 area is also shown. 
(fig. 1) to use the European data set of past vertical-incidence soundings most effectively and to avoid the problems that arise at the higher and/or lower latitudes (Bradley, 1995 and references therein).

One of the objectives of the current COST 251 Action on Improved Quality of Ionospheric Telecommunication Systems Planning and Operation is to further refine these models and to widen their geographical area of applicability to $70^{\circ} \mathrm{N}$ northwards and $60^{\circ} \mathrm{E}$ eastwards (fig. 1). This area involves a part of the high latitude ionosphere with irregular spatial and temporal variability of the $F$ region and intense absorption in lower $E$ and $D$ regions. Results should lead to the creation of a more general method for the regional ionospheric mapping potentially applicable to any geographically restricted area (Hanbaba, 1996, 1997).

The following sections highlight some recent research efforts made by ionospheric COST scientists in the area of ionospheric mapping and modelling in general. Section 2 gives an overview of input specification upon which ionospheric mapping and testing procedures are built. Section 3 describes the current state-ofthe-art in regional ionospheric mapping. Section 4 provides a brief summary of testing procedures. Finally, a discussion on further efforts is given in Section 5.

\section{Database and indices}

It is a well-known fact that none of the existing modelling activities are rigorously firstprinciple, since they rely to some extent on empirically specified input conditions. The accuracy of these inputs limits the model abilities to develop required ionospheric specification. Therefore, in formulating any global and/or regional ionospheric modelling and mapping procedure the input specification aspects of the problem such as input database and solarterrestrial indices initially have to be addressed.

PRIME experience suggests that a sufficiently complete comprehensive database is required upon which to build our understanding of the ionosphere for map generation with measure- ments of relevant model parameters from as many locations as possible. Table I lists vertical-incidence ionosonde data included in the PRIME database, RAL database (Levy et al., 1996) and those yet to be included in the database under COST 251 Action auspices. Relevant ionospheric parameters to be used to specify the structure of the electron-density height profile models consist of the key ionospheric characteristics of the vertical incidence such as $f_{0} F_{2}, M(3000) F_{2}, f_{0} F_{1}$ and $f_{0} E$ that are also used to predict operational parameters in HF telecommunication systems.

Database for map testing with the best achievable geographical coverage of accurate measurements for a variety of geophysical conditions is needed and therefore must not be included in the database for map generation (Levy et al., 1998). Favourable comparisons should be made between model predictions and measured data under a variety of solar and geomagnetic conditions that describe both the steady state characteristics and the dynamic response of the ionosphere.

The idea of the ionospheric indices for long-term predictions and short-term forecasting relies on the assumption that the key ionospheric characteristics are associated in a systematic way with certain measurable quantities concerned with solar and geomagnetic activities. However, a different index should be used for the $F_{2}$ layer from that used for the $E$ and $F_{1}$ layers because the causative physical mechanisms at high latitude are certainly different and independent. A consistent and reasonably long series of ionospheric and solar-terrestrial observations made possible the investigation of the merit of new monthly, daily and disturbance indices of ionospheric state above the COST 251 areas such as those of Mikhailov (1998), Perrone and De Franceschi (1998), Muhtarov and Kutiev (1998) and Cander (1998a).

A new method for the $M F_{2}$ index long-term prediction has been developed by Mikhailov (1998). It is based on the relationship of monthly $M F_{2}$ with $R_{12}$ index, which is officially long-term predicted. Although the $M F_{2}$ relationship with $R_{12}$ is the worst (compared to the relationship with ionospheric indexes such as 
Table I. Vertical-incidence ionosonde data.

\begin{tabular}{|c|c|c|c|c|c|c|c|}
\hline Station name & $\begin{array}{l}\text { URSI } \\
\text { code }\end{array}$ & $\begin{array}{c}\text { Geographic } \\
\text { latitude }\end{array}$ & $\begin{array}{l}\text { Geographic } \\
\text { longitude }\end{array}$ & $\begin{array}{c}\text { COST } 238 \\
\text { years }\end{array}$ & $\begin{array}{l}\text { WDC CD 1\&2 } \\
\text { years }\end{array}$ & $\begin{array}{c}\text { RAL CD } \\
\text { years }\end{array}$ & $\begin{array}{c}\text { COST } 251 \\
\text { years }\end{array}$ \\
\hline Arkangelsk & AZ163 & $64.4 \mathrm{~N}$ & $40.5 \mathrm{E}$ & & $69-90$ & $69-92, * 93$ & $69-93$ \\
\hline Ashkhabad & AS237 & $37.9 \mathrm{~N}$ & $58.3 \mathrm{E}$ & & $57-90$ & $57-92, * 93,94-95$ & $57-99$ \\
\hline Athens & AT138 & $38.0 \mathrm{~N}$ & $23.6 \mathrm{E}$ & $61-87$ & & & \\
\hline Bekescaba & BH148 & $46.7 \mathrm{~N}$ & $21.1 \mathrm{E}$ & & $64-89$ & $64-89$ & $64-90$ \\
\hline Beograd & BE145 & $44.8 \mathrm{~N}$ & $20.5 \mathrm{E}$ & $64-93$ & & & $93-99$ \\
\hline Budapest & BU147 & $47.4 \mathrm{~N}$ & $19.2 \mathrm{E}$ & $67-76$ & $57-59$ & $57-59$ & $57-66$ \\
\hline Chilton (RAL) & & $51.5 \mathrm{~N}$ & $358.7 \mathrm{E}$ & & & & 93-99 \\
\hline De Bilt & DT053 & $52.1 \mathrm{~N}$ & $5.2 \mathrm{E}$ & $67-76$ & $57-81$ & $57-81$ & $57-66,77-87$ \\
\hline Dourbes & DB049 & $50.1 \mathrm{~N}$ & $4.6 \mathrm{E}$ & $69-88$ & $57-89$ & $57-89$ & $57-68,89-99$ \\
\hline El Arenosillo & & $37.1 \mathrm{~N}$ & $353.2 \mathrm{E}$ & $93-94$ & & 93 & 74-92,95-99 \\
\hline Freiburg & FR048 & $48.1 \mathrm{~N}$ & $7.6 \mathrm{E}$ & $48-76$ & $57-74$ & $57-74$ & \\
\hline Garchy & GY042 & $47.3 \mathrm{~N}$ & $3.1 \mathrm{E}$ & $61-73$ & & & \\
\hline Gibilmanna & GM037 & $37.6 \mathrm{~N}$ & $14.0 \mathrm{E}$ & $76-91$ & $76-90$ & $76-93, * 94$ & $92-99$ \\
\hline Gorki & GK156 & $56.1 \mathrm{~N}$ & $44.2 \mathrm{E}$ & & $59-89$ & $59-89$ & $58-91$ \\
\hline Istanbul & & $41.1 \mathrm{~N}$ & $29.0 \mathrm{E}$ & $93-94$ & & & \\
\hline Juliusruh & JR055 & $54.6 \mathrm{~N}$ & $13.4 \mathrm{E}$ & $61-93$ & $57-90$ & $57-95$ & $57-60,94-99$ \\
\hline Kalininarad & KL154 & $54.7 \mathrm{~N}$ & $20.6 \mathrm{E}$ & $64-93$ & $64-90$ & $64-92, * 93, * 94$ & $94-99$ \\
\hline Kiev & KV151 & $50.5 \mathrm{~N}$ & $35.5 \mathrm{E}$ & $64-92$ & $64-90$ & $64-92, * 93$ & $93-99$ \\
\hline Kiruna & KI167 & $67.8 \mathrm{~N}$ & $20.4 \mathrm{E}$ & & $57-86$ & $57-86, * 91,92-95$ & $57-99$ \\
\hline Lannion & LN047 & $48.7 \mathrm{~N}$ & $356.6 \mathrm{E}$ & $71-93$ & $71-89$ & $71-89$ & $94-99$ \\
\hline Lerwick & LE061 & $60.1 \mathrm{~N}$ & $358.8 \mathrm{E}$ & & & & $91-99$ \\
\hline Lindau & LI050 & $51.6 \mathrm{~N}$ & $10.1 \mathrm{E}$ & $64-76$ & $70-79$ & $70-79$ & $77-79$ \\
\hline Lisbon & LE038 & $38.8 \mathrm{~N}$ & $350.8 \mathrm{E}$ & $87-92$ & $87-89$ & $87-89$ & \\
\hline Loparskaya & MM168 & $68.0 \mathrm{~N}$ & $33.0 \mathrm{E}$ & & $57-90$ & $57-92, * 93, * 94$ & $83-99$ \\
\hline Lycksele & LY164 & $64.6 \mathrm{~N}$ & $18.8 \mathrm{E}$ & & $57-89$ & $57-95$ & $57-99$ \\
\hline Miedzeszyn & MZ152 & $52.2 \mathrm{~N}$ & $21.2 \mathrm{E}$ & $60-85$ & $58-85$ & $58-85$ & $58-99$ \\
\hline Moskow & MO155 & $55.5 \mathrm{~N}$ & $37.3 \mathrm{E}$ & & $57-90$ & $57-92, * 93,94-95$ & $45-99$ \\
\hline Murmansk & MM168 & $69.0 \mathrm{~N}$ & $33.0 \mathrm{E}$ & & & & $57-86$ \\
\hline Nikosia & & $35.1 \mathrm{~N}$ & $33.2 \mathrm{E}$ & & & & $90-99$ \\
\hline Nurmijarvi & NU159 & $60.5 \mathrm{~N}$ & $24.6 \mathrm{E}$ & & $57-87$ & $57-87$ & $57-87$ \\
\hline Poitiers & РT046 & $46.6 \mathrm{~N}$ & $0.3 \mathrm{E}$ & $57-94$ & $57-89$ & $57-89, * 92$ & $95-99$ \\
\hline Pruhonice & PQ052 & $50.0 \mathrm{~N}$ & $14.6 \mathrm{E}$ & $58-93$ & $58-79$ & $58-79$ & $94-99$ \\
\hline Rome & RO041 & $41.9 \mathrm{~N}$ & $12.5 \mathrm{E}$ & $49-91$ & $58-90$ & $58-94$ & $92-99$ \\
\hline Rostov & RV149 & $47.2 \mathrm{~N}$ & $39.7 \mathrm{E}$ & & $57-80$ & $57-80,91-95, * 93$ & $49-99$ \\
\hline Slough & SL051 & $51.5 \mathrm{~N}$ & $359.4 \mathrm{E}$ & $67-90$ & $57-90$ & $57-95$ & $31-66,91-95$ \\
\hline Sodankyla & SO166 & $67.3 \mathrm{~N}$ & $26.6 \mathrm{E}$ & & $57-89$ & $57-89$ & $57-99$ \\
\hline Sofia & SQ143 & $42.7 \mathrm{~N}$ & $23.4 \mathrm{E}$ & $64-94$ & $64-74$ & $64-74$ & $62-63,95-99$ \\
\hline South Uist & US057 & $57.4 \mathrm{~N}$ & $7.3 \mathrm{E}$ & $85-89$ & $85-89$ & $85-89$ & $69-84,90$ \\
\hline St. Peter Or. & PE054 & $54.3 \mathrm{~N}$ & $8.6 \mathrm{E}$ & $83-91$ & $83-90$ & $83-91, * 92$ & \\
\hline St. Petersburg & LD160 & $59.9 \mathrm{~N}$ & $30.7 \mathrm{E}$ & & $57-90$ & $57-92, * 93,94-95$ & $49-99$ \\
\hline Sverdlovsk & SL256 & $56.4 \mathrm{~N}$ & $58.6 \mathrm{E}$ & & $57-90$ & $57-92, * 93,94, * 95$ & $57-99$ \\
\hline Tbilisi & TB142 & $41.7 \mathrm{~N}$ & $44.8 \mathrm{E}$ & & $63-86$ & $63-86$ & $63-86$ \\
\hline Tortosa & EB040 & $40.8 \mathrm{~N}$ & $0.5 \mathrm{E}$ & $68-93$ & & $92-93$ & $57-67,94-99$ \\
\hline Tromso & TR169 & $69.7 \mathrm{~N}$ & $19.0 \mathrm{E}$ & & 58 & 58 & $57-78 ?$ \\
\hline Uppsala & UP158 & $59.8 \mathrm{~N}$ & $17.6 \mathrm{E}$ & $65-92$ & $57-89$ & $57-89,91-95$ & $57-91,93-99$ \\
\hline
\end{tabular}


$\left.I F_{2_{12}}, I G_{12}, M F_{2_{12}}\right)$, this approach allows us to improve (compared to the ITU-R approach) the $f_{0} F_{2}$ long-term prediction accuracy by $36 \%$, $26 \%$, and $24 \%$ for the 3,6 , and 12 months lead time correspondingly. Perrone and De Franceschi (1998) reviewed the most common solar, ionospheric and geomagnetic indices with particular reference to their application for radio communication prediction purposes. Summary tables of practical use have been also prepared and are included in the paper concerning the method of derivation of the indices, their time interval, their drawbacks, their time-history and the Internet node addresses where they are available. Muhtarov and Kutiev (1998) have developed a similar type of index as the basis of a new short-term prediction method in which regular monthly median variations of a given ionospheric characteristic are corrected by a factor which depends linearly on the associated auto-correlation function expressed in terms of $K_{p}$. It is separately evaluated for each measurement station using data collected over three solar cycles. Cander (1998a) has applied neural network techniques to the forecasting of hourly $f_{0} F_{2}$ and TEC using different solar-terrestrial indices. Results have been compared by this technique using measurement data for Slough and it has been concluded that whilst these techniques work well for predictions up to one hour ahead, there is little advantage in incorporating a solar or magnetic index dependence.

\section{Regional mapping techniques}

The study and application of regional mapping techniques, both for instantaneous and real time forecasting as well as for prediction of the median conditions, emerge from the need to improve their performances and use the available or a more dense network of ionospheric stations and, in a restricted area, to simplify, the difficulties. These advantages are evident in comparison with the global methods where one mathematical approach, despite its complexity, should allow for extreme and different situations with large inhomogeneity of data as in the oceans, very sparse or absent, or as in Europe, rather dense. On the other hand, it is not com- pletely obvious that a regional technique should always give better results than the global methods. In fact an incorrect application of the data bank or simply the use of non validated measurements of a poor network of ionospheric stations may emphasise «virtual» local variations, very far from the real behaviour. The study and development of global methods were performed in the past due to the wide application of ionospheric mapping to long distance HF radio links. Instead, relatively the trend to generate regional methods to obtain better results when these are interfaced with other geophysical models both for telecommunications as for geophysical modelling is relatively recent. The purpose to propose an organic study of different regional models to apply in the European area was an important task of the PRIME project. It was during this project that many regional mapping methods were developed, examined and tested in their application to the European area and finally compared with the performances of the most used global method that is the ITU-R (1994).

Some of these models like SIRM, PASHA, MQMF2 and EOF were initiated before the PRIME project started and were developed and improved in recent years using the updated data bank and submitted to the testing procedure in the final form. Other models like KGRID, LINLAT and UNDIV were generated in the context of the PRIME project involving studies towards a new mapping procedure based on the agreement to allow for solar cycle variations in long term maps by grouping all data together irrespective of the epoch and for the rising or falling half cycles and to assume a parabolic dependence for $f_{0} F_{2}$ and a linear dependence for $M(3000) F_{2}$ on the 12-monthy smoothed sunspot number $\mathrm{R}_{12}$ (Kouris et al., 1994)

\subsection{SIRM (Simplified Ionospheric Regional Model)}

The Simplified Ionospheric Regional Model (SIRM) (Zolesi et al., 1993) is a regional long term prediction model based on the Fourier analysis of the monthly medians of the ionospheric characteristics coming from the ob- 

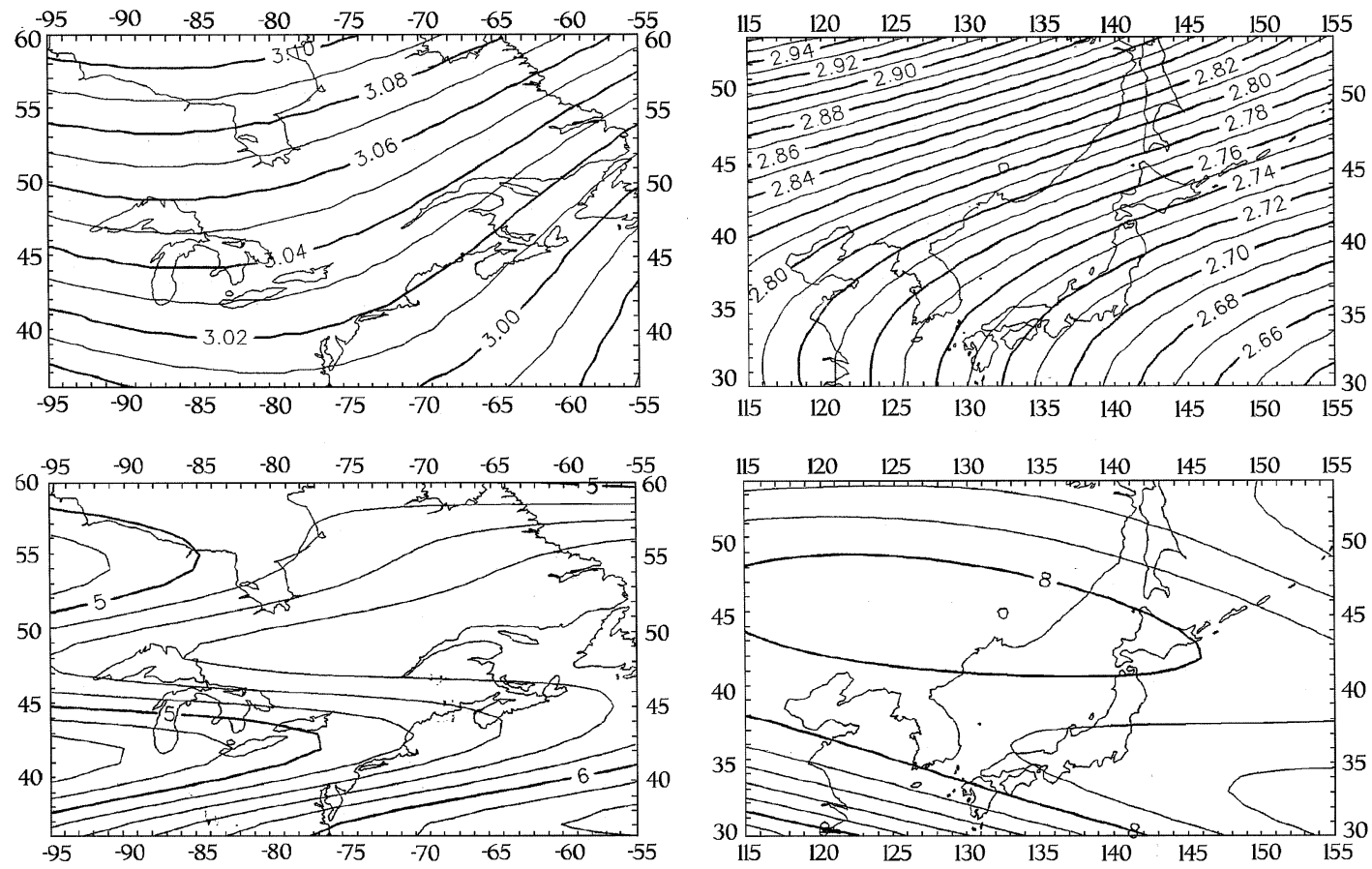

Fig. 2a. Maps of monthly median $M(3000) F_{2}$ values, above, and $f_{0} F_{2}$ values, below, calculated with SIRM in North West America and North East Asia.

served data of an inhomogeneous and sparse network of ionospheric stations and expressed as a function of the geographic coordinates, the universal or local time and of the mean value of $R_{12}$. Starting from a simple station model for each station given by a linear regression analysis of the ionospheric parameter versus solar index activity, it was shown that only 12 dominant Fourier coefficients are sufficient to reproduce the main features of the diurnal, seasonal and solar cycle behaviour of the mid-latitude ionosphere under median conditions

$$
f_{0} F_{2 h, m}=A_{0}+\sum_{n}^{l} A_{n} \sin \left(\frac{2 \pi n t}{T}+Y_{n}\right)
$$

where $f_{0} F_{2}$ is the critical frequency of the $F_{2}$-layer, $n$ is the harmonic number and $T$ is a period corresponding to one year. Considering that the numerical coefficients $A_{n}$ and $Y_{n}$ have, at first approximation, a linear behaviour on the solar activity $R_{12}$ and assuming that, in a restricted area, they depend only on LT and on the geographical latitude they may easily be calculated by a linear regression of the Fourier coefficients of every station versus their latitude and for two levels of solar activity. The procedure first developed to model the main ionospheric characteristics over Europe was then applied also in other mid-latitude areas both in the northern and southern hemisphere (Zolesi et al., 1996). Figure 2a shows an example of maps related to the median $M(3000) F_{2}$ and $f_{0} F_{2}$ values calculated by SIRM over North East America and North East Asia for June 1988 at 12000 UT when the solar activity was $R_{12}=94$

Recently an updated version of SIRM has been made to be applied to the extended area of 
foF2

Jan. $1981 \mathrm{R} 12=140$

Lannion 48.7 N $356.6 \mathrm{E}$

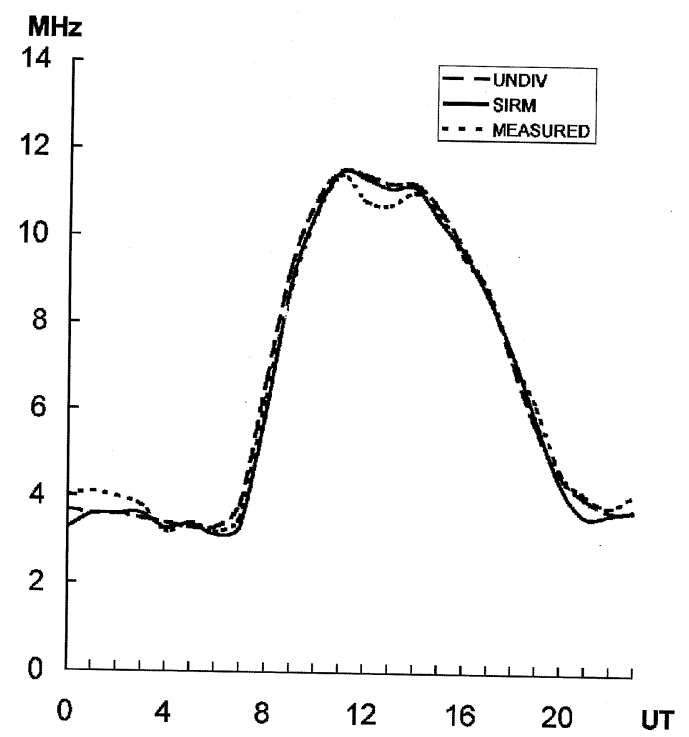

Arkangelesk $63.3 \mathrm{~N} 40.5 \mathrm{E}$

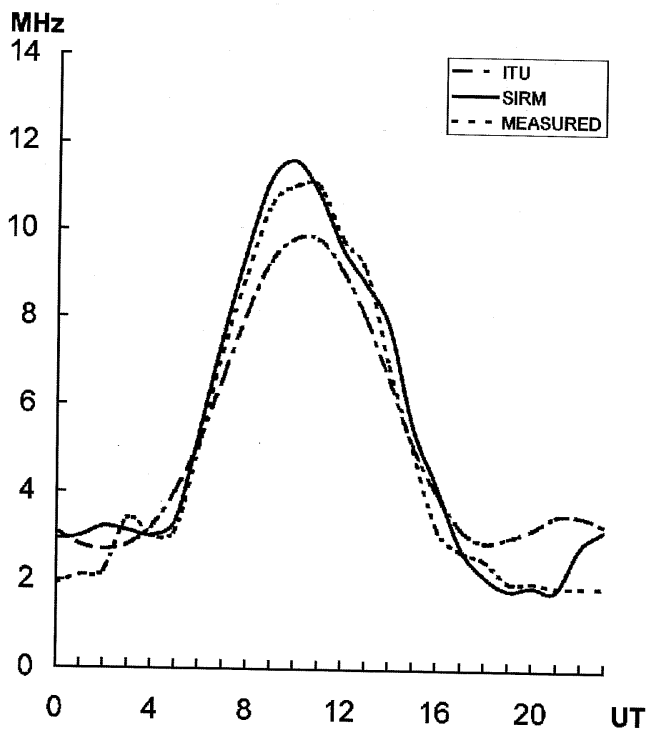

Fig. 2b. Hourly behaviours of $f_{0} F_{2}$ values measured in two COST 251 ionospheric stations compared with the predicted values by ISIRM and UNDIV in Lannion and by ISIRM and ITU in Arkangelesk.

north and near East Europe and to take into account the consequences of high latitude regions. The model is still based on the Fourier coefficients from the analysis of the median monthly values of the ionospheric parameters measured in the stations collected under the COST 251 project but in this case, to better reproduce the monthly behaviour, the Fourier analyses were performed month by month instead of along the two virtual years of the two solar epochs. The performance of the improved SIRM applied on the European region are very similar to the UNDIV model and/or better than the ITU global model (fig. 2b).

Poor results were instead obtained at extremely high latitude as observed at Kiruna ionospheric station $(67.8 \mathrm{~N})$, during winter and high solar activity, mainly due to the more complex physical mechanism of ionization and to the lack of hourly data that reduces the valid- ity of the monthly median computation. The improved SIRM is still a very simple procedure, not only for its easy mathematical formulation and for the reduced number of numerical coefficients, but above all for the short software program that can be easily used and linked with other software procedures.

\subsection{PASHA (regional long term prediction of ionospheric parameters by Adjusted Spherical Harmonic Analysis)}

The PASHA procedure is based on the SCHA (Spherical Cap Harmonic Analysis) technique which has been used for modelling the geomagnetic field over a limited region of the Earth globe (Haines, 1985; De Santis, 1992). This technique depends on an expansion in Fourier longitudinal series and in fractional Legendre 

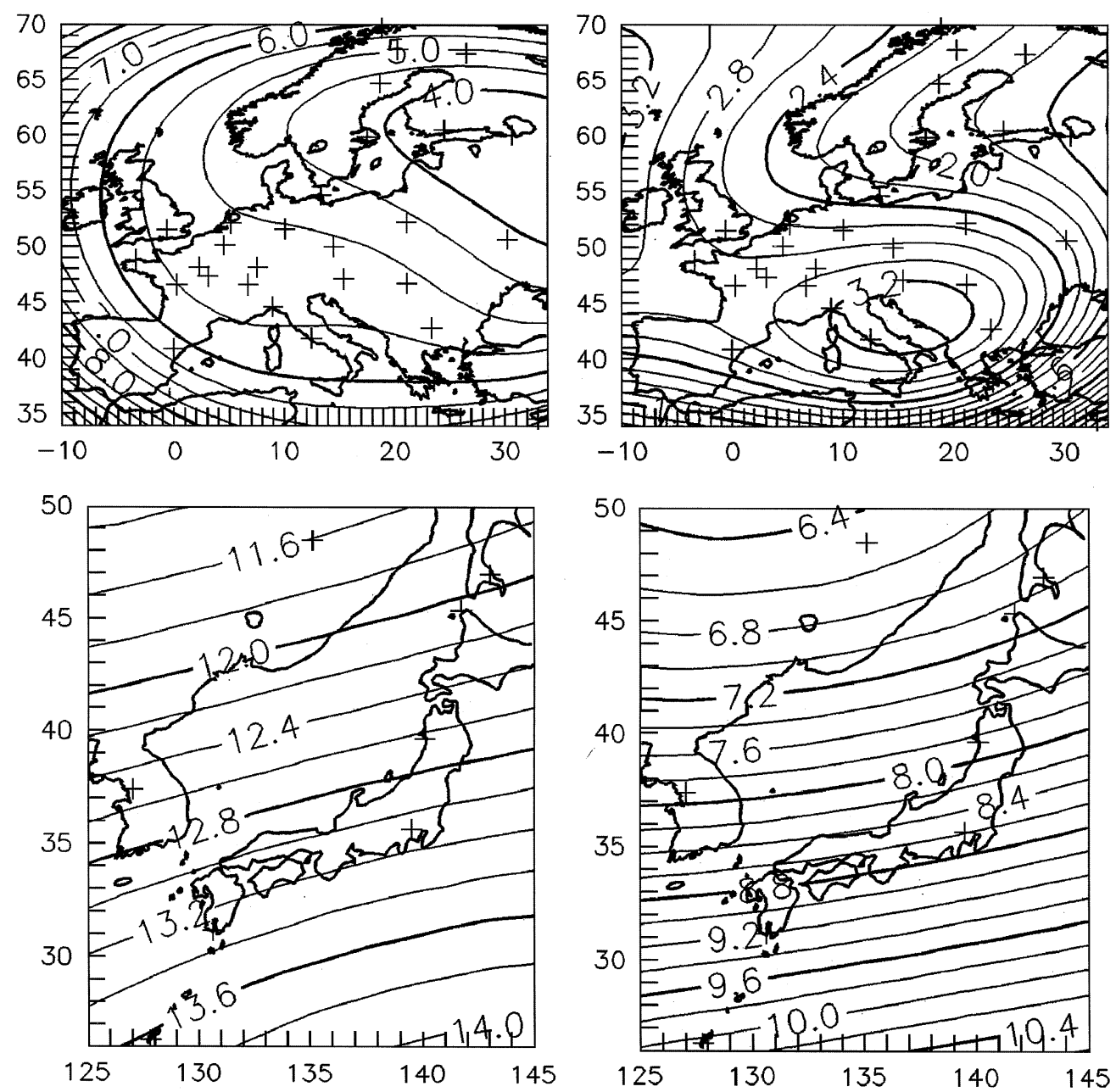

Fig. 3. Maps of monthly median $f_{0} F_{2}$ values for Europe and East Asia at 00 UT for March with $R_{12}=108$ (at the left), $R_{12}=21$ (right) calculated with PASHA.

colatitudinal functions $P_{n_{k}}^{m}(\cos \theta)$ of integer order $m$ and non-integer degree $n_{k}$, where $\theta$ is the colatitude. SCHA was used to map the monthly medians of the critical frequency of the $F_{2}$ layer, $f_{0} F_{2}$, over a suitable cap including Europe. It has been shown that nine expansion coefficients are sufficient for an accurate description of the main features of $f_{0} F_{2}$, at fixed year, month and time of the day (De Santis et al., 1991).
An important improvement in the technique applied to ionospheric parameters was obtained with ASHA (Adjusted Spherical Harmonic Analysis) that consists in the enlargement of the spherical cap into the hemisphere, including the region of interest (De Santis et al., 1994). In this way the real degree $n_{k}$ may be replaced by the integer value $k$ so the simpler and more practical conventional Legendre colatitudinal function may be used. In the new reference sys- 
tem $f_{0} F_{2}$ can be expressed in a 2D function of the spatial coordinates

$$
\begin{aligned}
& f\left(\lambda, \theta^{\prime}\right)=\sum_{k=0}^{K} \sum_{m=0}^{k}\left(g_{k}^{m} \cos (m \lambda)+\right. \\
& \left.+h_{k}^{m} \operatorname{sen}(m \lambda)\right) \cdot P_{k}^{m}\left(\cos \left(\theta^{\prime}\right)\right)
\end{aligned}
$$

where $\lambda$ is the transformed geographic longitude, $\theta^{\prime}$ the adjusted colatitude while the coefficients $g_{k}^{m}$ and $h_{k}^{m}$ may be determined by a least square fit of the observed data. The ASHA technique was then adapted for long-term ionospheric prediction in a restricted area, by introducing the solar dependence of the selected ionospheric parameter into the ASHA expansion coefficients that can be calculated like the previous one by a least squares fit of the observed data (De Franceschi and De Santis, 1994). This procedure, called PASHA (Prediction with ASHA), has also been applied in the Asiatic region and Australian region. In fig. 3 there are two examples of $f_{0} F_{2}$ maps.

\subsection{EOF (Empirical Orthogonal Function)}

The Empirical Orthogonal Functions (EOF) method was developed for global and regional long term modelling of ionospheric parameters (Dvinskikh, 1988; Dvinskikh and Naiedova, 1991). The descriptives of EOF are defined as the eigenfunctions of the autocorrelation matrix of the data field. Following expansion into EOF, the following was chosen for ionospheric parameters:

$$
\begin{gathered}
f\left(t, s, R_{12}, x, y\right)= \\
=\sum_{i=1}^{L} \sum_{j=1}^{M} \sum_{k=1}^{N} X_{i}(t) Y_{i j}(s) Z_{i j k}\left(R_{12}\right) V_{i j k}(x, y)
\end{gathered}
$$

where $X_{i}(t)$ characterises the hourly variation, $Y_{i j}(s)$ characterises the annual variation, $Z_{i j k}\left(R_{12}\right)$ describes the dependence of the solar activity $R_{12}$ and $V_{i j k}(x, y)$ are the expansion coefficients characterising the geographic variation. The EOF regional model was derived in particular for the critical frequency of $E, F_{1}, F_{2}$ and
$M(3000) F_{2}$ plus the probability of occurrence of the $F_{1}$ layer. Although regional application of the EOF model is limited between $40^{\circ}-70^{\circ} \mathrm{N}$ in latitude and $0^{\circ}-150^{\circ} \mathrm{E}$ in longitude, it has the advantage of high compactness and considerably reduces computing time (Singer and Taubenheim, 1990).

\subsection{UNDIV the PRIME recommended long term mapping method}

The UNDIV model is the long term mapping procedure recommended by the COST238 for use in the European area and adopted after tests in comparison with other developed methods. According to the PRIME results (Kouris et al., 1994; Bradley et al., 1994), the solar cycle dependence on $f_{0} F_{2}$ has been conveniently quantified for each station, month and hour by reference values within the low, medium and high epoch bands for $R_{12}=35, R_{12}=85$ and $R_{12}=$ $=135$ while in the case of $M(3000) F_{2}$ it has been given for $R_{12}=35$ and $R_{12}=135$. The mapping data set for the new method consists of $\Omega_{1}, \Omega_{2}$ and $\Omega_{3}$ values of 16 stations for $f_{0} F_{2}$ and $\Omega_{4}$ and $\Omega_{5}$, data values of 15 stations for $M(3000) F_{2}$. Considering that $f_{0} F_{2}$ and $M(3000) F_{2}$ can be expressed by

$$
\begin{gathered}
f_{0} F_{2}=a+b \cdot R_{12}+c \cdot R_{12}^{2} \\
M(3000) F_{2}=d-e \cdot R_{12}
\end{gathered}
$$

and if $\Omega_{1}, \Omega_{2}, \Omega_{3}$ are the values of $f_{0} F_{2}$ for $R_{12}=35,85,135$ respectively determined by a parabolic regression and $\Omega_{4}$ and $\Omega_{5}$ the values of $M(3000) F_{2}$ for $R_{12}=35$ and 135 determined by a linear regression, then:

$$
\begin{aligned}
& a=2.295 \cdot \Omega_{1}-1.890 \cdot \Omega_{2}+0.595 \cdot \Omega_{3} \\
& b=-0.044 \cdot \Omega_{1}+0.068 \cdot \Omega_{2}-0.024 \cdot \Omega_{3} \\
& c=0.0002 \cdot \Omega_{1}+0.0004 \cdot \Omega_{2}+0.0002 \cdot \Omega_{3} \\
& d=1.35 \cdot \Omega_{4}-0.35 \cdot \Omega_{5} \\
& e=0.01 \cdot\left(\Omega_{4}-\Omega_{5}\right) .
\end{aligned}
$$

Bearing in mind that in the European mid- 
latitude region there is no significant geomagnetic control in comparison with high latitude or extended regions the simple geographical coordinates were adopted. Then assuming that in a restricted area no first order longitude effect may be taken into account, only a linear dependence on geographical latitude was adopted for each of the $\Omega$ coefficients for all $24 \mathrm{~h}$ of local time and for all 12 months. For each of the $24 \times 12$ local time values the linear dependence with latitude was found by a linear regression using the observed data of a selected number of ionospheric stations reserved to generating the numerical coefficients. Mathematical algorithms are finally incorporated to calculate Universal Time or not integer local time transpositions. Figure 4 gives a $3 \mathrm{D}$ display and isolines calculated by UNDIV for $f_{0} F_{2}$.
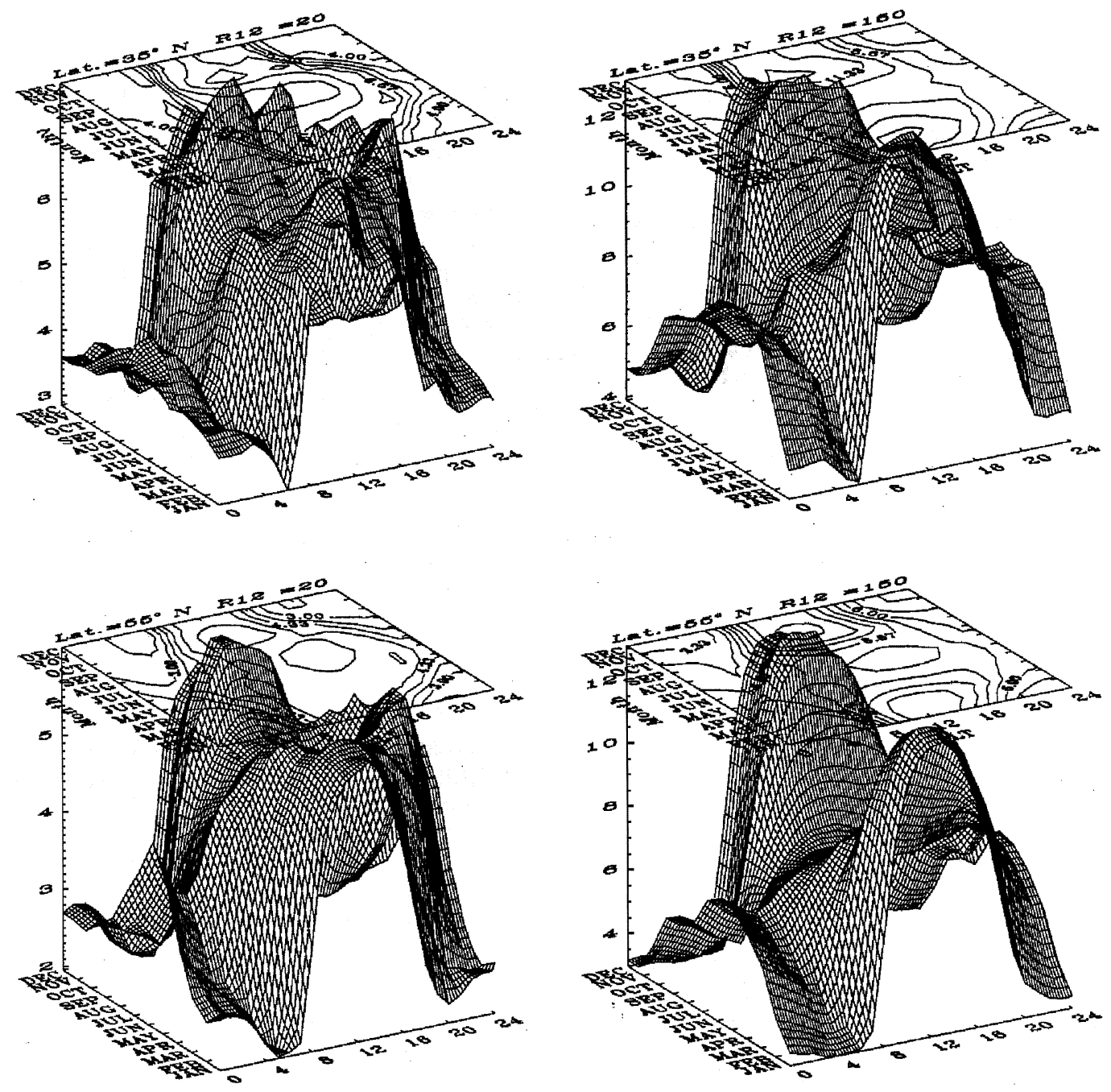

Fig. 4. 3D display and isolines given by UNDIV for monthly median $f_{0} F_{2}$. 


\section{5. $M Q M F_{2}$ (Multiquadric Method of spatial interpolation based on $f_{0} F_{2}$ versus $\mathrm{MF}_{2}$ regression)}

$M Q M F_{2}$ is a long term prediction method first developed for worldwide median mapping (Mikhailov et al., 1990) and then applied to the European region to model $f_{0} F_{2}$ and $M(3000) F_{2}$ ionospheric characteristics. Data observed during the period 1957 to 1990 and coming from 28 ionospheric stations, for $f_{0} F_{2}$, and from 19 stations, for $M(3000) F_{2}$, were used to establish the model inside the main area, from $30^{\circ} \mathrm{N}$ to $70^{\circ} \mathrm{N}$ as latitude and from $10^{\circ} \mathrm{W}$ to $60^{\circ} \mathrm{W}$ as longitude, including the European region. A buffer zone where the $f_{0} F_{2}$ and $M(3000) F_{2}$ are calculated according to the ITU-R model is also considered to interface the regional model with the external or global area.

The $M Q M F_{2}$ is based on the ionospheric in$\operatorname{dex} M F_{2}$ (Mikhailov and Mikhailov, 1995) and on the multiquadric (MQ) method of spatial interpolation (Teryokhin and Mikhailov, 1992) for which a selected ionospheric parameter is represented by

$$
\begin{gathered}
f=\sum_{i=1}^{n} C_{i}\left[1-\sin \theta \sin \theta_{i} \cos \left(\varphi-\varphi_{i}\right)-\right. \\
\left.-\cos \theta \cos \theta_{i}\right]^{\frac{1}{2}}
\end{gathered}
$$

where $\theta$ is the geographic colatitude, $\varphi$ is the geographic longitude and the $C_{i}$ is a set of numerical coefficients.

The $M F_{2}$ monthly ionospheric index has been produced for the period 1949-1992. For the future the index may be calculated so long as there are available 10 ionospheric stations at least with $f_{0} F_{2}$ noon values to which a regression analysis may be applied using the well known McNish-Lincoln procedure. Maps obtained with $M Q M F_{2}$ procedure for $f_{0} F_{2}$ and $M(3000) F_{2}$ are given in figs. 5 and 6 respectively.

\section{6. $K G R I D$}

KGRID is a method substantially based on the Kriging interpolation and contouring technique. Considering that most geophysical pa- rameters can vary continuously and their variation from place to place is so erratic that no simple mathematical expression can describe it the Kriging theory applies a weighted interpolation to calculate the autocorrelation between adjacent data points where the weights depend on the distance separation as was given by a particular parameter called semivariogram (Oliver and Webster, 1990).

The procedure was applied to the reference monthly sets of Omega coefficients calculated for $R_{12}=35,85,135$ the $f_{0} F_{2}$ and for $R_{12}=35$, 135 the $M(3000) F_{2}$ to generate values on 4 latitude $\times 8$ longitude encompassing the PRIME area (Samardjiev et al., 1993). A map obtained by this procedure is given in fig. 7 .

\subsection{LINLAT}

The LINLAT computer program provides estimates of monthly median $f_{0} F_{2}$ and $M(3000) F_{2}$ within a regional area as a function of geographic latitude and longitude, months and UT. It is based on empirical relations fitted to a multistation data set of measured values like the $\Omega$ coefficients quoted above. It has been shown (Bradley et al., 1994) that the diurnal variation expressed in LT is essentially independent of location and this can be represented by separate hourly values with Fourier interpolation for non integer times. Then the 24-h mean $f_{0} F_{2}$ is approximately a linear function of latitude and shows no discernible dependence, while $M(3000) F_{2}$ has no systematic latitude variation and is taken to be completely independent of location. The complete mapping procedure involves 1476 numerical coefficients coming from the 24 integer LT values for each month, for each of the five $\Omega$ terms and $12 \times 3$ coefficients as the latitude gradient variation.

\subsection{Single station models}

Mapping techniques based on single station model are the typical home made mapping methods produced in many ionospheric prediction services both for long-term and short-term predictions (Stanislawska et al., 1991; Moraitis 


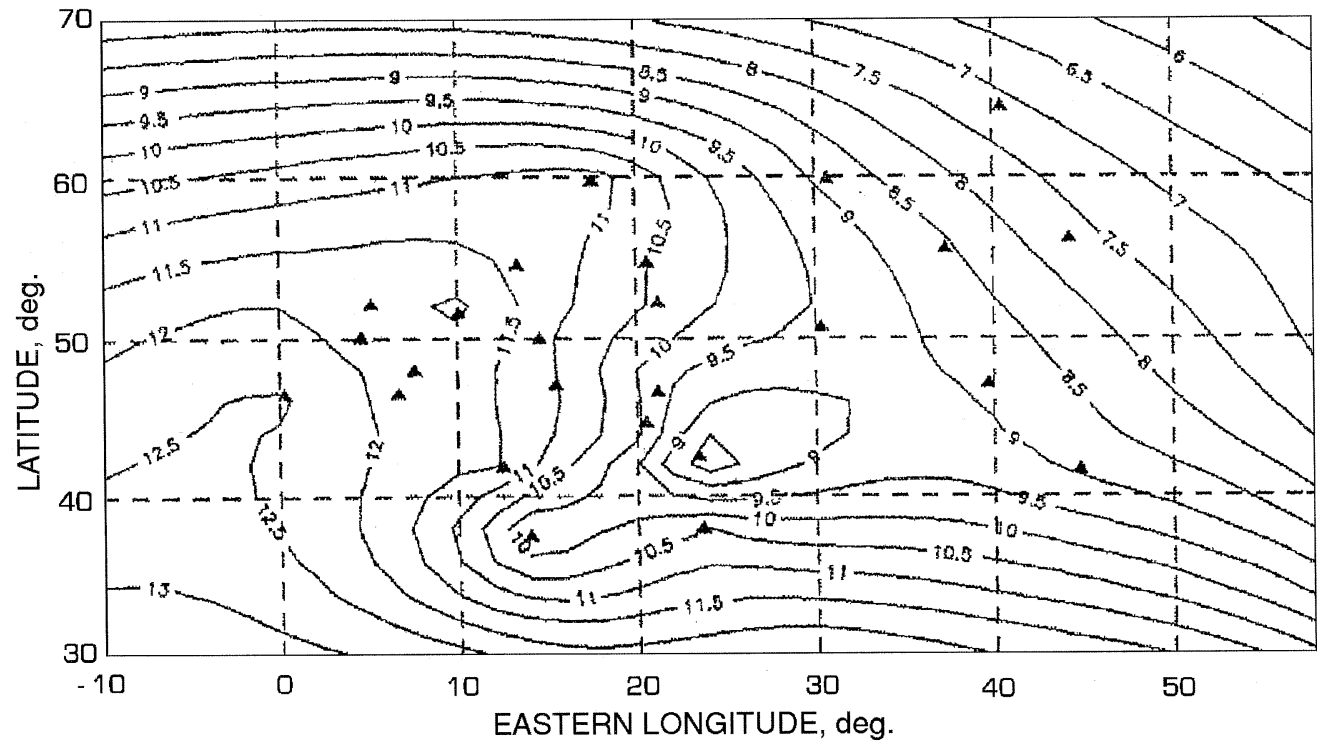

Fig. 5. Map of monthly median $f_{0} F_{2}$ calculated with $M Q M F_{2}$ for February 1979 at 16 UT.

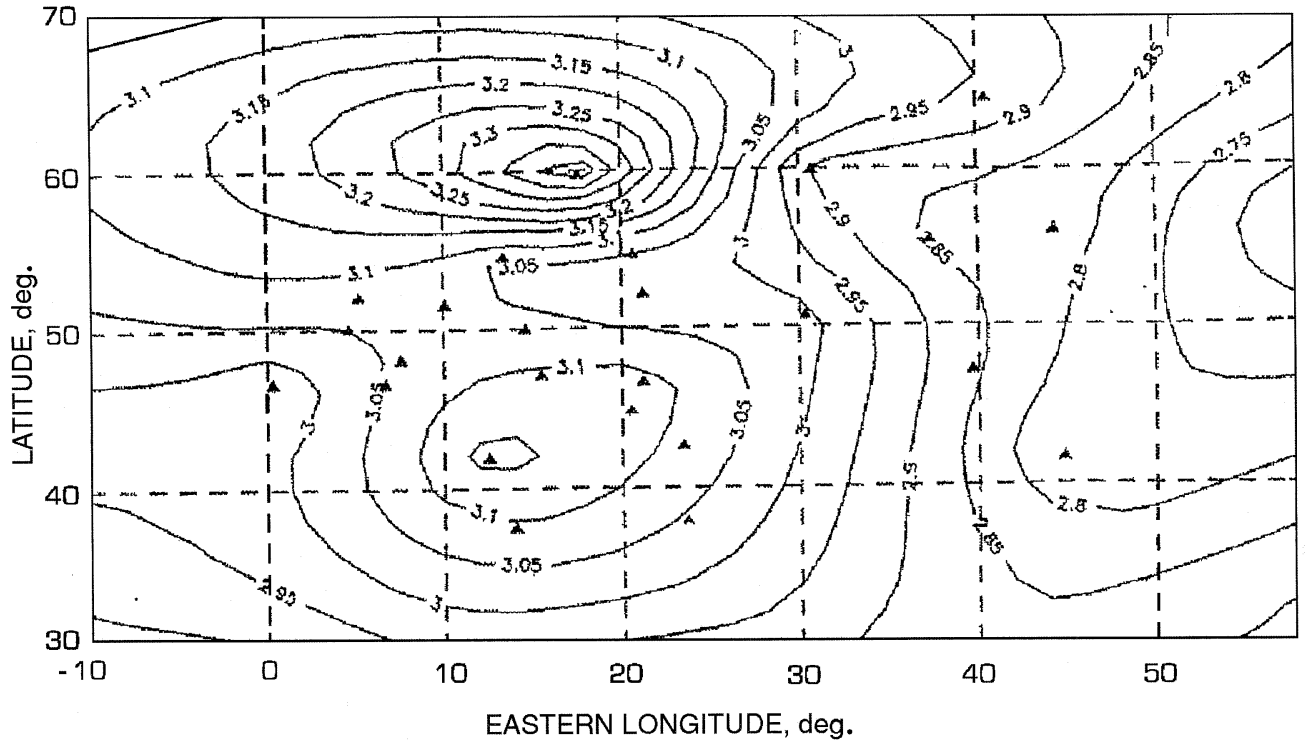

Fig. 6. Map of monthly median $M(3000) F_{2}$ calculated with $M Q M F_{2}$ for February 1979 at 16 UT. 


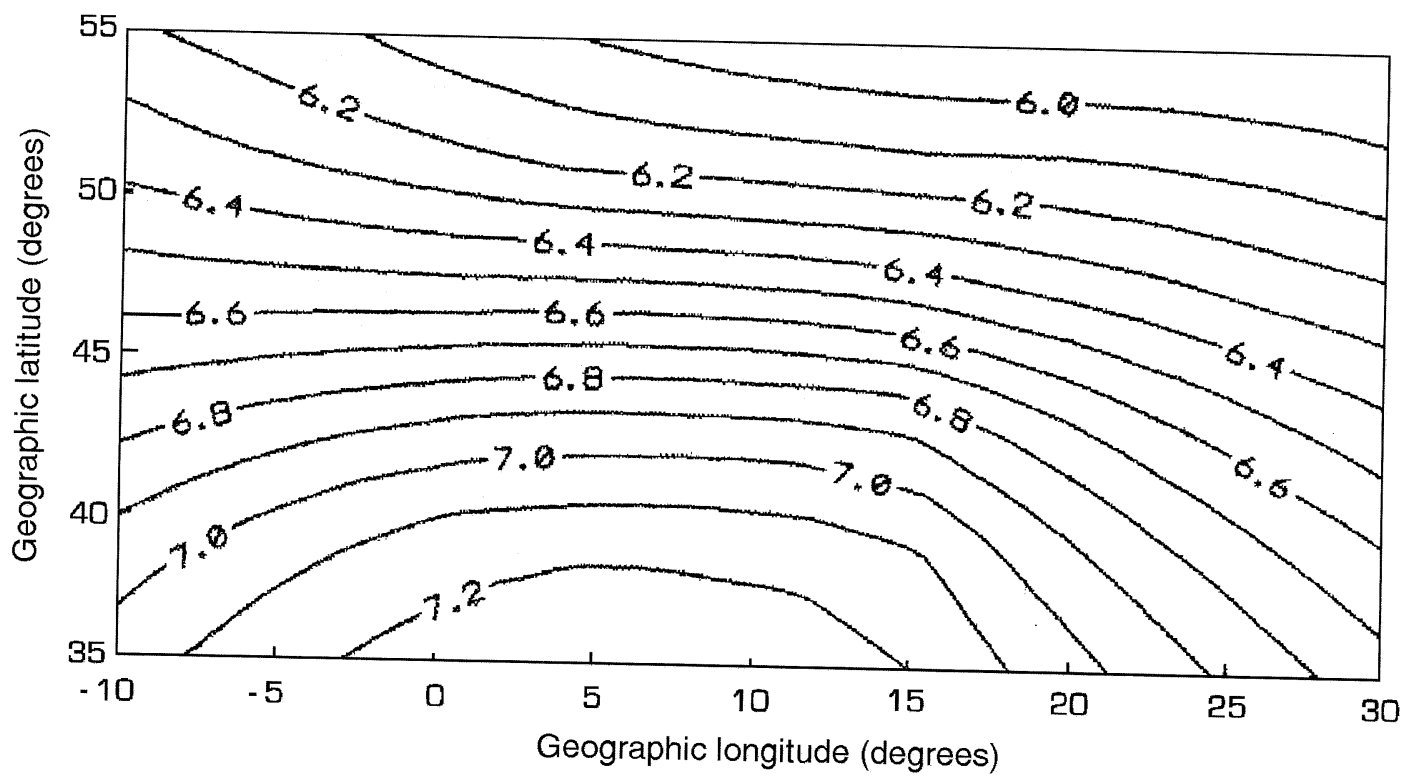

Fig. 7. Map of monthly median $f_{0} F_{2}$ calculated with KGRID for June 16 UT with $R_{12}=56.1$.

et al., 1991; Cander et al., 1993; Vasiljevic et al., 1995). These models are very important not only for local or short distance telecommunication purposes but, for their accuracy, also for interface with other geophysical models such as the electron density profiles or total electron content determination. The models are obviously based on the accurate study of the behaviour of one station characterised by a long history of observations (Dominici and Zolesi, 1987).

\section{Mapping testing procedure}

An efficient and complete test procedure is the final and only way to present, compare and validate the results of different mapping methods. Complete because few sparse comparisons between calculated and measured values do not give any certainty that the method may maintain the performances in time and space and efficient because its results should give a real ranking of the methods without any inclusion of arbitrary factors.
In the PRIME method (Bradley, 1995) a testing procedure was proposed and adopted where a figure of merit given by the formula

$$
F=\sqrt{\frac{1}{N_{t}} \sum_{N_{t}} \frac{1}{\left(N_{c}-1\right)} \sum_{N_{c}} W_{c}\left(\frac{T-M}{M}\right)^{2}}
$$

with $T$ the measured values, $M$ the mapped values, $N_{c}$ the number of values in a class, defined as the data set including all the available measured values for a specific location, sunspot ranges and seasons and $N_{t}$ the total number of classes taken into account of a weighting factor $W_{c}$ related to the quality and the geographical distribution of the ionospheric stations. Then the choice of weighting factors and distribution of the stations given for map generation with respect to those chosen for map testing may include an arbitrary alteration of results. Otherwise, the simple application of a standard deviation procedure cannot consider different kinds of measurements but should be preceeded by a careful analysis and validation of the data com- 
ing from the ionospheric stations. This can be done by single station models as a reference or other measurements such as TEC or satellite data.

A new testing procedure in the frame work of the COST 251 project concerning longterm and instantaneous mapping of $f_{0} F_{2}$ and $M(3000) F_{2}, N(h)$ profiles models and buffer zone problem has been studied and appropriate recommendations are given by Levy et al. (1998). This procedure is to choose the official COST 251 mappings and models which will be incorporated in the COST 251 computer program.

\section{Summary of results and future directions}

The past several years have seen an increased sophistication in ionospheric modelling and emphasis in scientific campaigns involving model comparisons with multi-day to multi-long observations in such efforts as the PRIME and IIST investigations within the COST 238 and 251 projects. There have also been significant advances in empirically documenting magnetic storm effects in the ionosphere (e.g., Bradley et al., 1997; Cander, 1998b; Cander and Mihajlovic, 1998). The trend towards developing climatological and weather specifications of the ionosphere brings with it the need to understand and accurately model and map both quiet and disturbed conditions in near real time mode.

Regarding the regional ionospheric modelling and mapping of the standard ionospheric characteristics, we must conclude that the PRIME progress has been substantial, with newlydeveloped methods being used to finally deal realistically with such a restricted area as PRIME area (Bradley, 1995). However, despite the strong recent mapping progress, one must be concerned for the future, particularly from the observational point-of-view. Existing PRIME methods are based on empirical climatology that yields an average ionosphere where the average is taken over very different ionospheric patterns, i.e. an average data over very different ionospheric conditions corresponding to the same solar activity level. For COST 251 model- ling activities persistent features of the COST 251 area such as the subauroral trough, auroral oval may be smeared out because of the averaging process and any empirical model that does not organise the data as for all of driving forces that govern the ionosphere will have this property. Moreover, empirical climatology is limited by the amount of data and the spatial and temporal distribution of that data.

On the other hand, theoretical climatology yields a representative ionosphere that corresponds to a potentially realisable set of specified geophysical conditions. It is limited by the accuracy and completeness of the ionospheric physics and aeronomy chemistry included in the theoretical models. The COST 251 mapping procedure could be based upon the modification of monthly median ionospheric parameters given by existing PRIME models extended in area by the use of formulations that characterise specific features of the high latitude ionosphere. The parameters determined by the numerical coefficients or specific equations can be modified by inclusion of the auroral oval, the $F_{2}$ region ionisation trough, the ionisation due to auroral $E$ layer formation, auroral absorption and electron-density irregularities in the $E$ and $F$ regions of the polar ionosphere.

As an alternative to classical methods of time series ionospheric prediction, the artificial neural network methods have been studied (Cander, 1998c) and new types of models are proposed (Lamming and Cander, 1998a,b). Nonlinearity of the ionospheric prediction problem was the reason to use time series prediction capabilities of artificial neural networks for its solution. Furthermore, the classical ionospheric forecasting models developed up to now depend on successful solar and magnetospheric forecasts and limited knowledge of solarmagnetospheric fields limits ionospheric forecasting significantly. As Cander (1998c) has shown the artificial neural networks are currently quite successfully used in various fields including solar and terrestrial parameters prediction and modelling. However, it is important to remember that particular neural network model for a given time series has to be carefully chosen to reach a required performance. For the generation of the new COST 251 
monthly median mapping and instantaneous procedures and short-term forecasting technique, the artificial neural networks should be used and compared with conventional techniques to evaluate the advantages.

\section{REFERENCES}

BiLiTZA, D. (1992): Solar-terrestrial models and application software, Planet. Space Sci, 40, 541-579.

BRAdLeY, P.A. (1995): PRIME (Prediction and Retrospective Ionospheric Modelling over Europe), Final Report, ECSC-EEC-EAEC, Brussels.

Bradley, P.A., LJ.R. CANDER, M.I. Dick, J.-C. Jodogne, S.S. Kouris, R. Leitinger, W. Singer, Th.D. Xenos, and B. ZOLESI (1994): The December 1993 new mapping meeting, in Proceeding of the COST 238 Workshop on "Numerical Mapping and Modelling and their Application to PRIME», Eindhoven, May 1994, COST238TD(94)10, 169-179.

Bradley, P.A., LJ.R. CANDER, I. KuTIEV and R. HANBABA (1997): PRIME (COST 238) studies of ionospheric storm effects, Adv. Space Res., 20 (9), 1669-1678.

CANDER, LJ.R. (1998a): On solar-terrestrial indices for short-term ionospheric forecasting by neural networks, in Proceedings of the 2nd COST 251 Workshop «Algorithms and Models for COST 251 Final Product», edited by A. VERNON, COST251TD(98)005, 30-31 March 1998, Side, Turkey, 44-48.

CANDER, LJ.R. (1998b): Space weather effects on telecommunication, in AI Applications in Solar-Terrestrial Physics, ESA WPP-148 Proceedings, edited by I. SANDAHL and E. JONSSON, European Space Agency, Paris, 35-42.

CANDER, LJ.R. (1998c): Artificial neural network applications in ionospheric studies, Ann. Geofis., 41 (5-6), 757-766 (this issue).

CANDER, LJ.R. and S.J. MiHAJLOVIC (1998): Forecasting ionospheric structure during the great geomagnetic storms, J. Geophys. Res., 103 (A1), 391-398.

CANDER, LJ.R., I. STANislawsKa, G. Moraitis, H. SizUn and E.M. Apostolov (1993): How to use single station model in the context of PRIME Instantaneous mapping, in Proceedings of the COST238 Workshop on "PRIME Studies with Emphasis on TEC and Topside Modelling», Graz, May 1993, 271-274.

CANDER, LJ.R., B. Zolesi and P.A. BRAdLEY (1996): Status of available $N(h)$ model profiles, Ann. Geofis., 39 (4), 729-733

DE FRANCESCHI, G. and A. DE SANTIS (1994): PASHA: regional long term predictions ionospheric parameters by ASHA, Ann. Geofis., 37 (2), 209-220.

DE SANTIS, A. (1992): Conventional spherical harmonic analysis for regional modelling of the geomagnetic field, Geophys. Res. Lett., 19 (10), 1065-1067.

De Santis, A., G. De Franceschi, B. Zolesi, S. Pau and LJ.R. CANDER (1991): Regional of the critical frequency of the $F_{2}$ layer by spherical cap harmonic expansion, Ann. Geophysicae, 9, 401-406.
De Santis, A., G. De Franceschi and D.J. Kerridge (1994): Regional spherical modelling of 2D functions: the case of the critical frequency of the $F_{2}$ layer, Comp. Geosci., 20 (5), 849-871.

DOMINICI, P. and B. ZoLESI (1987): A model for normal ionosphere over Rome, Nuovo Cimento $C, \mathbf{1 0}$, 191-208.

DVINSKIKH, N.I. (1988): Expansion of ionospheric characteristics field in empirical orthogonal functions, $A d v$. Space Res., 8 (4), 179-187.

DVINSKIKH, N.I. and N.Y. NAIEDOVA (1991): An adaptive regional empirical ionospheric model, Adv. Space Res., $11(10), 7-10$

HAINES, G.V. (1985): Spherical cap harmonic analysis, $J$. Geophys. Res., 90 (B3), 2583-2591.

HanbabA, R. (1996): First Annual Report (Period July 1995-June 1996), COST251TD (96) 013.

Hanbaba, R. (1997): Second Annual Report (Period July 1996-June 1997), COST251TD (97) 010.

ITU-R (1994): CCIR reference ionosphere characteristics and methods of basic MUF, operational MUF and ray-path prediction, Recommendation ITU-R PI.434, International Telecommunication Union, Geneva.

JIAO, P.-N. and J. WU (1996): Ionospheric models and data for the Chinese subcontinent, Adv. Space Res., 18 (6), 191-200.

KouRIS, S.S., P.A. BRAdLEY and I.K. Nissopoulos (1994): The relationships of $f_{0} F_{2}$ and $M(3000) F_{2}$ versus $R_{12}$, in Proceedings of the COST 238 Workshop on «Numerical Mapping and Modelling and their Applications to PRIME», Eindhoven, May 1994, 103-117.

LAMMing, X. and LJ.R. CANDER (1998a): Monthly median ionospheric frequencies model using neural networks, in AI Applications in Solar-Terrestrial Physics, ESA WPP-148 Proceedings, edited by I. SANDAHL and E. JONSSON, European Space Agency, Paris, 229-234.

LAMMING, X. and LJ.R. CANDER (1998b): Monthly median $f_{0} F_{2}$ modelling over COST 251 area by neural networks, in Proceedings of the 2nd COST 251 Workshop "Algorithms and Models for COST 251 Final Product», edited by A. VERNON, COST251TD(98)005, 30-31 March 1998, Side, Turkey, 174-179.

LEVY, M.F., M.I. DICK and LJ.R. CANDER (1996): RAL Databank of VI Soundings, COST251TD (96) 020.

LeVy, M.F., M.I. Dick, P. SPalla, C. ScotTo, I. KuTIEV and P. Muhtarov (1998): COST 251 Testing Procedures, COST251TD(98)004.

MikhaILOV, A.V. (1998): A method for the ionospheric index $M F_{2}$ long-term prediction. An application to monthly median $f_{0} F_{2}$ long-term forecast, in Proceedings of the 2nd COST 251 Workshop «Algorithms and Models for COST 251 Final Product», edited by A. VERNON, COST251TD(98)005, 30-31 March 1998, Side, Turkey, 39-43.

Mikhailov, A.V. and V.V. Mikhailov (1995): Solar cycle variations of annual mean noon $f_{0} F_{2} A d v$. Space Res., 15 (2), 93-97.

Mikhailov, A.V., S.D. Buldenkova, V.V. MikhaIlov and YU.L. TERYOKHIN (1990): A comparison of solar activity indices for the purpose of modelling the monthly values of $f_{0} F_{2}$, Geomagn. Aeron., 30, 88-93. 
MoraITIS, G., Z.J. KeCIC and LJ.R. CANDER (1991): Ionospheric modelling at single stations, in Proceedings of the III PRIME Workshop, Rome, 154-160.

Muhtarov, P. and I. KuTIEV (1998): Geomagnetically correlated statistical model (GCSM) for short-term prediction of ionospheric parameters, in Proceedings of the 2nd COST 251 Workshop «Algorithms and Models for COST 251 Final Product», edited by. A. VERNON, COST251TD(98)005, 30-31 March 1998, Side, Turkey, 246-251.

OLIVER, M.A. and R. WeBSTER (1990): Kriging: a method of interpolation for geographical informations systems, Int. J. Geogr. Inf. Syst., 4 (3), 313-332.

Perrone, L. and G. DE FranCESCHI (1998): Solar, ionospheric and geomagnetic indices, Ann. Geofis., 41 (5-6), 843-855 (this issue).

RADICELLA, S.M. and M.-L. ZHANG (1995): The improved DGR analytical model of electron density height profile and total electron content in the ionosphere, Ann. Geofis., 38 (1), 35-41.

SamardJieV, T., P.A. Bradley, LJ.R. CANDER and M.I. DICK (1993): Ionospheric mapping by computer contouring techniques, Electron. Lett., 29 (20), 17941795.

Singer, W. and J. TAUBENHEIM (1990): Application of the expansion into empirical orthogonal functions to iono- spheric characteristics, Adv. Space Res., 10 (11), 59-64.

StanislawsKa, I., Z. KLOS, and K. STASIEwICZ (1991): Local models of the ionosphere based upon data from Miedzeszyn station, in Proceedings of the III PRIME Workshop, Rome, 161-164.

TERYOKHIN, YU.L. and A.V. MikhaIlov (1992): A new approach to solving the problem of a spatial approximation of the field of observed $f_{0} F_{2}$ values, Geomagn. Aeron., 32 (2), 205-210.

VASILJEVIC, I.M., LJ.R. CANDER and Z.J. KECIC (1995): POPAJ, a single station ionospheric model, in Proceedings of the COST238 Workshop on "Development and Testing of an Electron Density Profile Model for PRIME», El Arenosillo, 137-143.

Wu, J., K.-H. QuaN, K.-L. DAI, F.-G. LuO, X.-R. Sun, Z.-Q. LI, C. CAO, R.-Y. LIU and C.-S. SHEN (1996): Progress in the study of the Chinese reference ionosphere, Adv. Space Res., 18 (6), 187-190.

ZOLESI, B., LJ.R. CANDER and G. DE FranCESCHI (1993): Simplified ionospheric regional model for telecommunication application, Radio Sci., 28 (4), 603-612.

Zolesi, B., LJ.R. CANDER and G. DE FRANCESCHI (1996): On the potential applicability of the simplified ionospheric regional model to different mid latitude areas, Radio Sci., 31 (3), 547-552. 